\title{
Carbon monoxide pollution is associated with decreased lung function in asthmatic adults
}

\author{
C. Canova*, S. Torresan*, L. Simonato*, M.L. Scapellato*, R. Tessari" ${ }^{\#}$ A. Visentin*, \\ M. Lotti* and P. Maestrelli*
}

ABSTRACT: The aim of the present study was to test the effects of exposure to air pollutants on lung function.

A panel of 19 adult asthmatics living in Padua (Italy) was followed for five 30-day periods during 2 yrs consecutively (1,492 morning and 1,434 evening measures analysed). Peak expiratory flow (PEF) and forced expiratory volume in $1 \mathrm{~s}$ (FEV1) were measured using a pocket electronic meter. Daily levels of air pollutants and meteorological variables were collected at outdoor city monitoring sites.

Significant inverse associations were observed between morning and evening PEF and carbon monoxide level $(p=0.01-0.03)$, without clear differences between lags ( $0-3$ days). An increment of $1 \mathrm{mg} \cdot \mathrm{m}^{-3} \mathrm{CO}$ was associated with a PEF variation ranging $-2.6-\mathbf{- 2 . 8} \%$. All effect estimates on PEF for $\mathrm{CO}$ remained significant and even increased after controlling for particles with a $50 \%$ cut-off aerodynamic diameter of $10 \mu \mathrm{m}$ (PM10), nitrogen dioxide and sulphur dioxide in single and multipollutant models. A similar trend was observed for $\mathrm{FEV}_{1}$, but the associations were nonsignificant. A nonsignificant inverse relationship between evening PEF and $\mathrm{SO}_{2}$ was also detected. PEF and FEV1 were not related to $\mathrm{PM}_{10}$ and $\mathrm{NO}_{2}$ concentrations.

The present results indicate that, in this panel of adult asthmatics, the worsening of lung function is associated with exposure to gaseous pollutants and occurs at levels of $\mathrm{CO}$ and $\mathrm{SO}_{2}$ lower than current European standards.

KEYWORDS: Air pollution, asthma, carbon monoxide, lung function, peak expiratory flow

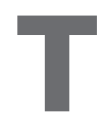
here is evidence that short-term exposure to gaseous air pollutants and particulate matter (PM) is associated with mortality and morbidity, in particular for cardiopulmonary diseases [1-3].

Epidemiological and clinical data suggest adverse health effects of air pollution, especially in populations with pre-existing respiratory disease, such as asthmatics [4-7]. Since asthma exacerbations are associated with bronchoconstriction, monitoring of lung function is a means of assessing the course of the disease. There is substantial evidence that lung function in asthmatic children is decreased by exposure to air pollution [8-15], whereas fewer studies are available in adult asthmatics [16-25], and the results are often controversial [16, 19-22, 24, 25].

Peak expiratory flow (PEF) measurements are widely used in epidemiological studies to assess the effects of air pollutants on pulmonary function. Although it has been established that forced expiratory volume in $1 \mathrm{~s}$ (FEV1) is an independent predictor of respiratory and cardiovascular mortality [26], this parameter has been investigated less as regards its relationship with air pollutants [11, 12, 14, 22, 24]. Moreover, most studies have focused on the relation between lung function and PM [11-17, 21, 22], although several further gases may be involved in the adverse effects of air pollution.

The present study was conducted within the framework of a longitudinal study funded by the local environmental protection agency (Regional Agency for Environmental Prevention and Protection in Veneto (ARPAV), Padua, Italy) on the effects of personal exposure to particles with a $50 \%$ cut-off aerodynamic diameter of $10 \mu \mathrm{m}$ (PM10). The aim was to test the effects of exposure to different outdoor air pollutants (PM10, nitrogen dioxide, sulphur dioxide and carbon monoxide) on lung function, as assessed

\section{AFFILIATIONS}

*Dept of Environmental Medicine and Public Health, University of Padua, Padua, and

\#Unit of Epidemiology, Dept of

Prevention, Local Hospital Units of Venice, Venice, Italy.

\section{CORRESPONDENCE}

C. Canova

Dept of Environmental Medicine and Public Health

University of Padova

Via Loredan 18

35151 Padova

Italy

E-mail: cristina.canova@unipd.it

Received:

March 172009

Accepted after revision:

July 242009

First published online:

Aug 132009 
by PEF and FEV1, in adult subjects with bronchial asthma living in Padua (Italy) and followed up for 2 yrs.

\section{MATERIALS AND METHODS Study design}

In order to identify the cohort of asthmatics, prescriptions of inhaled $\beta_{2}$-agonists, alone or in combination with corticosteroids (Anatomical Therapeutical Chemical code R03A), during the period 1999-2003 were considered. The total number of prescriptions of antiasthmatic drugs was 118,025, from which 23,207 subjects with $\geqslant 1$ prescription $\cdot \mathrm{yr}^{-1}$ were identified. In order to identify subjects with chronic asthma, the criterion of $\geqslant 1$ R03A prescription $\cdot \mathrm{yr}^{-1}$ for $3 \mathrm{yrs}$ consecutively was applied. Since the aim was to study young adult asthmatics with a moderate-to-severe degree of disease, subjects aged 15-44 yrs with the highest number of bronchodilator prescriptions were considered. Patients with $\geqslant 1$ prescription $\cdot \mathrm{yr}^{-1}$ for $3 \mathrm{yrs}$ consecutively, aged 15-44 yrs at the time of recruitment (June 2004) and belonging to the quartile with the highest number of drug prescriptions (mean of $>6$ prescriptions $\mathrm{yr}^{-1}$ for $3 \mathrm{yrs}$ ) were selected $(n=158)$. After linkage to the population archive, in order to confirm that the subjects were alive and living in Padua, the resulting cohort comprised 138 (87.3\%) subjects. From this cohort, a panel of 40 subjects was randomly sampled, using an implicit stratification method, and followed for five 30-days periods during 2 yrs consecutively, at times corresponding to various seasons: summer 2004, autumn 2004, winter 2005, summer 2005, and autumn 2005.

Lung function and outdoor air pollution were measured for $\sim 1$ month in each period for a total of 156 days.

The diagnosis of asthma was confirmed in all subjects by their history and lung function tests according to Global Initiative for Asthma (GINA) guidelines [27] prior to the start of the study. This selection method using the drug prescriptions population database identified a cohort of patients with asthma with a high percentage $(81 \%)$ of moderate-to-severe disease, higher than the $31 \%$ estimated in the overall population of asthmatics in Italy [28].

Atopy was assessed by skin-prick testing against a panel of aeroallergens (house dust mite, moulds, cat and dog dander, and tree and grass pollens) [29].

Current drug treatment was recorded at the beginning of each monitoring period. On inclusion, the subjects received a detailed explanation of the study and written consent was obtained. The study design was approved by the Ethics Committee of Padua University Hospital (Padua, Italy).

\section{Lung function measurements}

PEF and FEV1 were measured using a pocket electronic meter (Piko-1; QUBIsoft, Padua, Italy). The Piko-1 stored up to 96 readings, which could be downloaded to a computer. Each participant was trained in the use of the Piko-1, including breathing technique, proper positioning and maintenance of the instrument. Subjects were instructed to perform a forced vital capacity (FVC) manoeuvre in the standing position three times in the morning and three times in the evening before taking any respiratory medication. The highest of the PEF and FEV1 readings obtained during each session were selected as the results of the test by the Piko- 1 . The device included software to check the acceptability of forced expiratory manoeuvres, and unacceptable FVCs were rejected.

\section{Air pollution measurements}

Outdoor concentrations of $\mathrm{PM} 10, \mathrm{NO}_{2}, \mathrm{SO}_{2}$ and $\mathrm{CO}$ were measured continuously at two fixed sites within the city of Padua by the ARPAV. PM10 were collected on glass fibre filters using European Standardisation Committee sampling heads (Italian Standardisation Organisation 12341) connected to pumps (Explorer plus; Zambelli, Bareggio, Italy) at a flow rate of $38.3 \mathrm{~L} \cdot \mathrm{min}^{-1} . \mathrm{NO}_{2}, \mathrm{SO}_{2}$ and $\mathrm{CO}$ were measured according to national regulations with Thermo Environmental Instruments (K50312, K50313, K50314 and K50315; Philips, Eindhoven, the Netherlands). The ambient PM2.5 level was not measured at the time of the study. Temperatures, humidities and pressures were provided by the Meteorological Centre of ARPAV.

Daily 24-h mean PM10, $\mathrm{NO}_{2}, \mathrm{SO}_{2}$ and 8-h maximum moving average $\mathrm{CO}$ levels were considered for data analysis.

\section{Data analysis}

All 40 recruited subjects and those with at least a third of the expected measures (50 out of 156) were considered for the analyses.

The data were analysed via unpaired t-tests together with Chisquared tests, as appropriate, in order to compare the characteristics of the subjects with at least a third of expected measures with those of the remaining subjects.

The association between air pollutants and health outcomes were examined using marginal linear models for continuous variables, based on the generalised estimating equations (GEEs) proposed by ZEGER and LIANG [30]. This method generates robust estimators regardless of the specification of the covariance matrix, and, since autocorrelation is included in the covariance, coefficients can be interpreted as usual. The models were tested using the Stata (Stata Corporation, College Station, TX, USA) xtgee procedure (with the robust option, which produces valid SEM even if the correlations within the group are not as hypothesised by the specified correlation structure).

Separate regression models were run using morning and evening PEF and FEV1 as the dependent variables. All of the models included mean 24-h temperature, humidity and atmospheric pressure, along with current use of corticosteroids (yes / no) and smoking habit (yes/no) as confounders. The associations were examined with respect to the mean pollutant concentrations during the 24-h period ending at midday on the day on which PEF and FEV1 were measured (lag 0), the previous day (lag 1), 2 days previously (lag 2) and 3 days previously (lag 3 ), and to the cumulative exposures over the previous $0-1$ days (lag $0-1$ ) and $0-3$ days (lag $0-3$ ). Results from the analyses were reported as absolute changes in PEF and $\mathrm{FEV} 1$ per $10 \mu \mathrm{g} \cdot \mathrm{m}^{-3}$ increase in pollutant concentration (except for $\mathrm{CO}$, for which the unit increase was $1 \mathrm{mg} \cdot \mathrm{m}^{-3}$ ). Finally, bi-pollutant and multi-pollutant models were conducted in which $\mathrm{CO}$ and PM10 levels, $\mathrm{NO}_{2}$ levels, $\mathrm{SO}_{2}$ levels or levels of all pollutants were correlated with lung function. The same lag (lag 1) was evaluated simultaneously for each pollutant. 


\begin{tabular}{|c|c|c|c|}
\hline \multirow[t]{3}{*}{ TABLE 1} & $\begin{array}{l}\text { tics of the } \mathrm{s} \\
\text { s }\end{array}$ & dy subjec & by number \\
\hline & \multirow[t]{2}{*}{ All Subjects } & \multicolumn{2}{|c|}{ Measures } \\
\hline & & $>50$ & $\leqslant 50$ \\
\hline Subjects n & 40 & 19 & 21 \\
\hline Females & $20(50.00)$ & $13(68.42)$ & $7(33.33)^{\star}$ \\
\hline Age yrs & $39.2 \pm 7.8$ & $40.9 \pm 6.4$ & $37.6 \pm 8.7$ \\
\hline \multicolumn{4}{|l|}{ Corticosteroid therapy } \\
\hline None & $13(32.50)$ & $8(42.11)$ & $5(23.81)$ \\
\hline Low dose & $9(22.50)$ & $3(15.79)$ & $6(28.57)$ \\
\hline Medium dose & $10(25.00)$ & $6(31.58)$ & $4(19.05)$ \\
\hline High dose & $8(20.00)$ & $2(10.53)$ & $6(28.57)$ \\
\hline \multicolumn{4}{|l|}{ Asthma severity ${ }^{\#}$} \\
\hline Intermittent & $3(7.50)$ & $2(10.53)$ & $1(4.76)$ \\
\hline Mild persistent & $5(12.50)$ & $2(10.53)$ & $3(14.29)$ \\
\hline Moderate persistent & $13(32.50)$ & $6(31.58)$ & 7 (33.33) \\
\hline Severe persistent & $19(47.50)$ & $9(47.37)$ & $10(47.62)$ \\
\hline Smokers & $14(35.00)$ & $3(15.79)$ & $11(52.38)^{*}$ \\
\hline \multicolumn{4}{|c|}{$\begin{array}{l}\text { Data are presented as mean } \pm \text { SD or } n(\%) \text { unless otherwise indicated. }{ }^{*} \text { : Global } \\
\text { Initiative for Asthma classification of asthma severity. }{ }^{*}: p<0.05 \text { (Chi-squared } \\
\text { test). }\end{array}$} \\
\hline
\end{tabular}

All tests were two-sided, and a p-value of $<0.05$ was considered significant.

All analyses were performed using the statistical package Stata (Stata software version 8).

\section{RESULTS}

Baseline demographic data are presented in table 1. No differences were observed between the subjects with more than a third of the measures $(n=19)$ and the remaining subjects $(n=21)$ with regard to age (mean $39 \mathrm{yrs})$, corticosteroid therapy $(68 \%)$ and asthma severity $(80 \%$ with moderate or severe persistent asthma), whereas differences were found with regard to sex $\left(\mathrm{X}^{2}=4.9 ; \mathrm{p}=0.027\right)$ and smoking status $\left(X^{2}=5.8 ; p=0.015\right)$. The following results refer only to the 19 subjects with at least a third of measures, in order to include people who consistently attended the longitudinal study.

\begin{tabular}{|c|c|}
\hline TABLE 2 & $\begin{array}{l}\text { Peak expiratory flow (PEF) and forced expiratory } \\
\text { volume in } 1 \mathrm{~s}(\mathrm{FEV} 1) \text { descriptive statistics in } \\
\text { subjects with }>50 \text { measures }\end{array}$ \\
\hline \multicolumn{2}{|l|}{ PEF L. $\min ^{-1}$} \\
\hline Morning & $327.1 \pm 107.4$ \\
\hline Evening & $336.8 \pm 115.3$ \\
\hline \multicolumn{2}{|l|}{ FEV1 L } \\
\hline Morning & $2.3 \pm 0.7$ \\
\hline Evening & $2.4 \pm 0.7$ \\
\hline
\end{tabular}

Data are presented as mean \pm SD $(n=1,492$ morning measures; $n=1,434$ evening measures of each parameter). ${ }^{*}: n=19$.

\begin{tabular}{|c|c|c|c|c|}
\hline \multirow[t]{2}{*}{ TABLE 3} & \multirow[b]{2}{*}{ Mean \pm SD } & \multirow[b]{2}{*}{ Median } & \multirow[b]{2}{*}{ Minimum } & \multirow[b]{2}{*}{ Maximum } \\
\hline & & & & \\
\hline $\mathrm{PM}_{10} \mu \mathrm{g} \cdot \mathrm{m}^{-3}$ & $56.98 \pm 32.25$ & 50.65 & 12.00 & 188.00 \\
\hline $\mathrm{NO}_{2} \mu \mathrm{g} \cdot \mathrm{m}^{-3}$ & $51.04 \pm 12.57$ & 50.51 & 19.16 & 90.41 \\
\hline $\mathrm{SO}_{2} \mu \mathrm{g} \cdot \mathrm{m}^{-3}$ & $3.57 \pm 2.86$ & 2.64 & 0.46 & 12.78 \\
\hline $\mathrm{CO} \mathrm{mg} \cdot \mathrm{m}^{-3}$ & $1.72 \pm 1.00$ & 1.3 & 0.6 & 5.2 \\
\hline Temperature ${ }^{\circ} \mathbf{C}$ & $15.12 \pm 8.29$ & 15.18 & -2.33 & 28.18 \\
\hline Relative humidity \% & $74.11 \pm 15.21$ & 72.51 & 40.85 & 98.44 \\
\hline Barometric pressure $\mathrm{hPa}$ & $1014.56 \pm 4.88$ & 1014 & 1003 & 1029 \\
\hline \multicolumn{5}{|c|}{$\begin{array}{l}\text { Daily 24-h means were measured for all parameters except for carbon } \\
\text { monoxide level, for which the } 8 \text {-h maximum moving average was used, all at } \\
\text { two locations. PM10: particles with a } 50 \% \text { cut-off aerodynamic diameter of } \\
10 \mu \mathrm{m} \text {. }\end{array}$} \\
\hline
\end{tabular}

The distribution of the outcome variables during the study is presented in table 2 . The number of satisfactory observations of morning PEF and FEV1 was 1,492 (50.3\% of expected) and 1,434 (48.4\% of expected) considering the evening measures. PEF and FEV1 were lower in the morning, as expected in asthmatic subjects.

Mean air pollutant concentrations and meteorological parameters during the study period, as well as Pearson's correlation coefficients, are summarised in tables 3 and 4 . Mean and median concentrations of PM10 and $\mathrm{NO}_{2}$ were above the current daily European limits of $50 \mu \mathrm{g} \cdot \mathrm{m}^{-3}$ and $40 \mu \mathrm{g} \cdot \mathrm{m}^{-3}$, respectively. Conversely, none of the $\mathrm{SO}_{2}$ and $\mathrm{CO}$ concentrations exceeded the daily limits of $125 \mu \mathrm{g} \cdot \mathrm{m}^{-3}$ for $\mathrm{SO}_{2}$ and $10 \mathrm{mg} \cdot \mathrm{m}^{-3}$ for $\mathrm{CO}$ [31]. Significant correlations were found among all the four pollutants ( $\mathrm{r}$ from 0.48 between $\mathrm{CO}$ and $\mathrm{NO}_{2}$ to 0.68 between PM10 and $\mathrm{NO}_{2}$ ).

Figure 1 shows the relationship between lung function parameters and air pollutants for the 19 subjects. Significant inverse associations were observed between outdoor $\mathrm{CO}$ level and morning $(p=0.01-0.02)$ and evening PEF $(p=0.02-0.03)$, whereas no significant associations with FEV1 were observed $(\mathrm{p}=0.16-0.24)$. Increments of $\mathrm{SO}_{2}$ were associated with decrements of evening PEF, but the associations did not reach significance $(\mathrm{p}=0.09-0.19)$. There were no associations between PEF or FEV1 and PM10 or $\mathrm{NO}_{2}$ concentrations. No substantial differences between lags were observed. An increment of $1 \mathrm{mg} \cdot \mathrm{m}^{-3} \mathrm{CO}$ contributed to a variation in PEF which ranged $-2.6 \%$ (lag 2 morning PEF) to $-2.8 \%$ (lag $0-3$ evening PEF). An increment of $10 \mu \mathrm{g} \cdot \mathrm{m}^{-3} \mathrm{SO}_{2}$ contributed to a variation in respiratory function which ranged $-1.8 \%$ (lag 3 morning PEF) to $-4.6 \%$ (lag 3 evening PEF).

Similar results were observed when all 40 subjects were taken into consideration, although the associations were generally less significant. An increase in outdoor $\mathrm{CO}$ level was associated with a trend towards a decrease in morning PEF $(p=0.09-0.14)$, and with a significant decrease in evening PEF $(p=0.05-0.06)$. An increment of $1 \mathrm{mg} \cdot \mathrm{m}^{-3} \mathrm{CO}$ contributed to a variation in evening PEF of $\sim 2.15 \%$. Increments of $\mathrm{SO}_{2}$ were associated with a trend towards decrements in evening PEF $(p=0.06-0.09)$. An increment 
TABLE 4 Pearson's correlation coefficients for air pollutant concentrations and meteorological parameters during the 156 days studied

\begin{tabular}{|c|c|c|c|c|c|c|c|}
\hline & PM10 & $\mathrm{SO}_{2}$ & $\mathrm{NO}_{2}$ & $\mathrm{CO}$ & Temperature & Humidity & Pressure \\
\hline PM10 & - & - & - & - & - & - & - \\
\hline $\mathrm{SO}_{2}$ & $0.509^{\star \star \star}$ & - & - & - & - & - & - \\
\hline $\mathrm{NO}_{2}$ & $0.684^{* * *}$ & $0.535^{\star * *}$ & - & - & - & - & - \\
\hline co & $0.624^{\star \star \star}$ & $0.499^{\star \star \star}$ & $0.480^{\star \star \star}$ & - & - & - & - \\
\hline Temperature & $-0.529 * * *$ & $-0.564 * \star \star$ & $-0.480 * \star \star *$ & $-0.786^{\star \star \star}$ & - & - & - \\
\hline
\end{tabular}

PM10: particles with a 50\% cut-off aerodynamic diameter of $10 \mu \mathrm{m} .{ }^{*}: 0.05>p \geqslant 0.001 ; * \star *: p<0.001$.

of $10 \mu \mathrm{g} \cdot \mathrm{m}^{-3} \mathrm{SO}_{2}$ contributed to a variation in evening PEF of $\sim 4.2 \%$. No significant associations between PEF or FEV1 and PM10 or $\mathrm{NO}_{2}$ concentration were detected.

Little differences in the regression coefficients were observed when the data from the first and second year were considered separately (data not shown). However, this analysis was limited by the small number of data.

Table 5 shows the results of bi-pollutant and multi-pollutant models that focused on $\mathrm{CO}$ levels at lag 1 . Most effect estimates remained significant and some, in particular morning PEF,

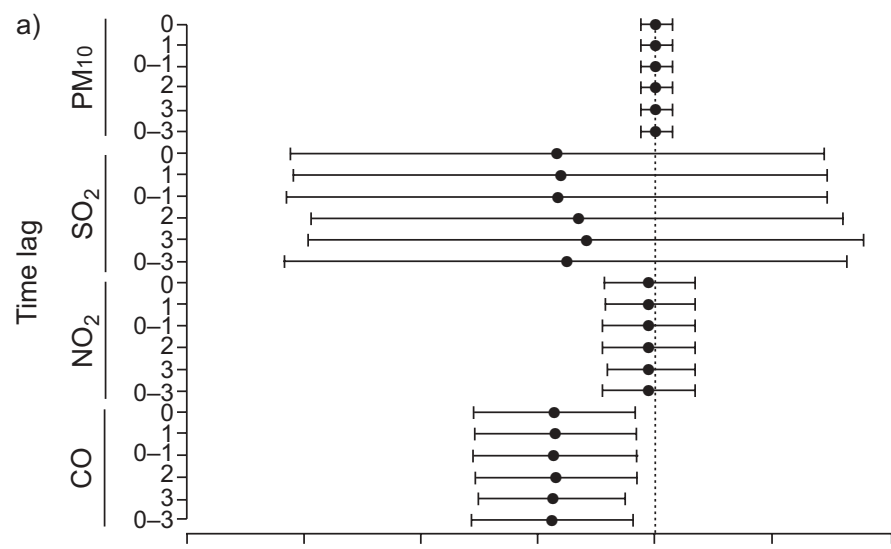

b)

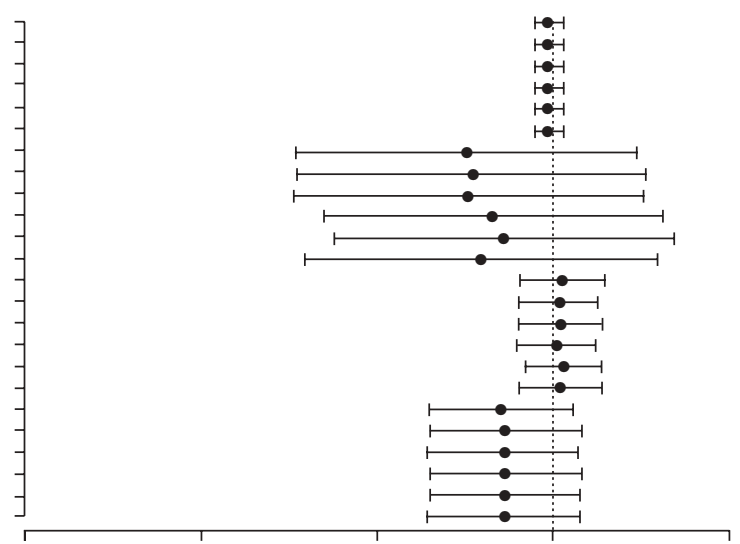

c)

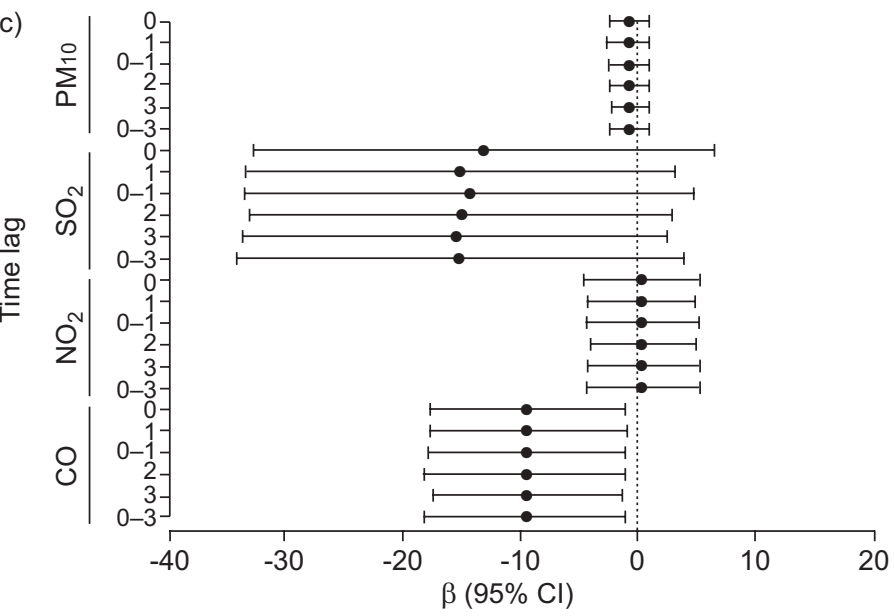

d)

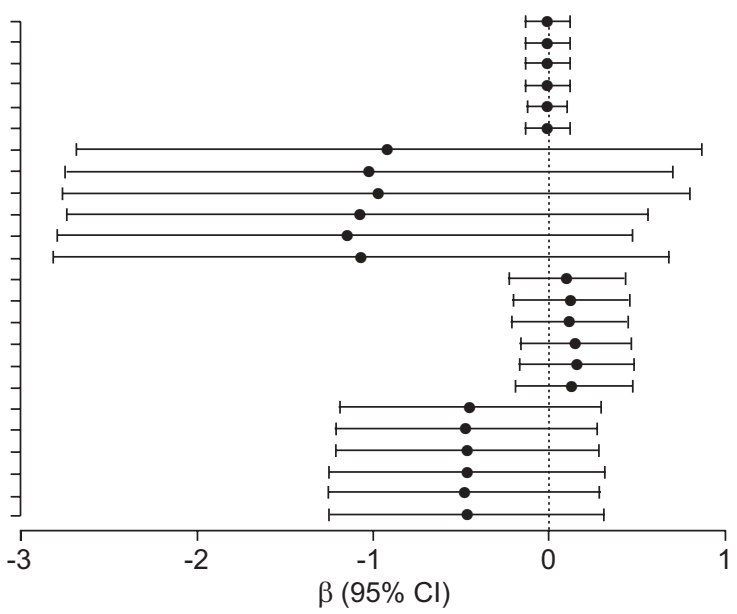

FIGURE 1. Relations between pollutant levels measured on the same day (lag 0), the previous day (lag 1), mean of 0-1 days (lag 0-1), 2 days previously (lag 2), 3 days previously (lag 3) and mean of 0-3 days (lag 0-3) and: a) morning peak expiratory flow (PEF); b) morning forced expiratory volume in $1 \mathrm{~s}$ (FEV1); c) evening PEF; and d) evening FEV1. PM10: particles with a 50\% cut-off aerodynamic diameter of $10 \mu \mathrm{m}$. $\beta$ : regression coefficient from generalised estimating equation models for panel data, controlling for temperature, relative humidity, atmospheric pressure, corticosteroid use and smoking habit (changes for $10 \mu \mathrm{g} \cdot \mathrm{m}^{-3}$ increase in pollutant concentration (except for $\mathrm{CO}$, for which the unit increase was $\left.1 \mathrm{mg} \cdot \mathrm{m}^{-3}\right)$ ); Cl: confidence interval. 
where the effect was the greatest, even grew larger after controlling for the other pollutants.

\section{DISCUSSION}

The present study shows that, in adult asthmatics living in Padua, increments of outdoor levels of $\mathrm{CO}$, and less clearly of $\mathrm{SO}_{2}$, were associated with decreases in lung function. No associations between PEF or FEV1 and PM10 or $\mathrm{NO}_{2}$ concentrations were observed.

In the present study, PEF was more sensitive than FEV1 at detecting relationship with air pollution. This may be surprising since both indices are derived from a single forced expiratory manoeuvre, and FEV1 is generally more sensitive at detecting bronchoconstriction under supervised laboratory conditions [32]. Since optimal FEV1 measurement is more technically demanding than that of PEF, the latter index is probably more suitable for home monitoring of lung function. Since the meter was provided with quality control software capable of discarding unsatisfactory expirations, we can be

\begin{tabular}{|c|c|c|c|}
\hline \multirow[t]{2}{*}{ TABLE 5} & \multicolumn{3}{|c|}{$\begin{array}{l}\text { Relations between lung function and carbon } \\
\text { monoxide level on the previous day (lag 1) in bi- } \\
\text { pollutant and multi-pollutant models } \#\end{array}$} \\
\hline & $\boldsymbol{\beta} \pm \mathrm{SEM}$ & $\mathrm{p}$-value & $\begin{array}{c}\text { Change per } \\
1 \mathrm{mg} \cdot \mathrm{m}^{-3} \mathrm{CO} \%\end{array}$ \\
\hline \multicolumn{4}{|l|}{ Morning PEF } \\
\hline None & $-8.50 \pm 3.54$ & 0.02 & -2.60 \\
\hline $\mathrm{SO}_{2}$ & $-8.23 \pm 3.41$ & 0.02 & -2.52 \\
\hline PM10 & $-10.52 \pm 4.18$ & 0.01 & -3.22 \\
\hline $\mathrm{NO}_{2}$ & $-8.64 \pm 3.52$ & 0.01 & -2.64 \\
\hline All pollutants & $-10.70 \pm 4.15$ & 0.01 & -3.27 \\
\hline \multicolumn{4}{|l|}{ Evening PEF } \\
\hline None & $-9.17 \pm 4.22$ & 0.03 & -2.72 \\
\hline $\mathrm{SO}_{2}$ & $-8.53 \pm 4.24$ & 0.04 & -2.53 \\
\hline PM10 & $-9.28 \pm 4.91$ & 0.06 & -2.76 \\
\hline $\mathrm{NO}_{2}$ & $-9.56 \pm 4.62$ & 0.04 & -2.84 \\
\hline All pollutants & $-9.18 \pm 4.89$ & 0.06 & -2.72 \\
\hline \multicolumn{4}{|l|}{ Morning FEV 1} \\
\hline None & $-0.03 \pm 0.02$ & 0.22 & -1.17 \\
\hline $\mathrm{SO}_{2}$ & $-0.03 \pm 0.02$ & 0.25 & -1.09 \\
\hline PM10 & $-0.03 \pm 0.03$ & 0.34 & -1.17 \\
\hline $\mathrm{NO}_{2}$ & $-0.03 \pm 0.02$ & 0.21 & -1.28 \\
\hline All pollutants & $-0.03 \pm 0.03$ & 0.34 & -1.18 \\
\hline \multicolumn{4}{|l|}{ Evening FEV1 } \\
\hline None & $-0.05 \pm 0.04$ & 0.21 & -1.98 \\
\hline $\mathrm{SO}_{2}$ & $-0.04 \pm 0.04$ & 0.24 & -1.77 \\
\hline PM10 & $-0.05 \pm 0.04$ & 0.20 & -2.24 \\
\hline $\mathrm{NO}_{2}$ & $-0.05 \pm 0.04$ & 0.16 & -2.22 \\
\hline All pollutants & $-0.05 \pm 0.04$ & 0.22 & -2.19 \\
\hline
\end{tabular}

$\beta$ : regression coefficient from generalised estimating equation models for panel data, controlling for temperature, relative humidity, atmospheric pressure, corticosteroid use and smoking habit (changes for $1 \mathrm{mg} \cdot \mathrm{m}^{-3}$ increase in pollutant concentration); PEF: peak expiratory flow; PM10: particles with a $50 \%$ cut-off aerodynamic diameter of $10 \mu \mathrm{m}$; FEV 1 : forced expiratory volume in $1 \mathrm{~s}$. Bold values represent significant results. \#: after adjustment for the various pollutants indicated. reasonably confident that erroneous values were excluded from the data set.

Although PM10 and $\mathrm{NO}_{2}$ levels frequently exceeded the current European standards of 50 and $40 \mu \mathrm{g} \cdot \mathrm{m}^{-3}$, respectively, throughout the study period, it was not possible to show any significant inverse association of PM10 with PEF and FEV1 deviations. This may reflect the low within-season variation in particulate mass levels in urban air in Padua. These findings agree with those of HARRÉ et al. [33], who reported that PEF wasn't significantly affected by PM10 in patients with COPD. Similarly, BRAUER et al. [34], in a panel of COPD adults, and GIRARDOT et al. [35], in a panel of healthy adults, found only trends for decreases in FEV1 and PEF related to ambient air PM. PETERS et al. [16] found that the effects of $\mathrm{SO}_{2}$ and PM on adults with a history of asthma were smaller and less consistent than on asthmatic children. PENTTINEN et al. [21] found that the daily mean number concentration of particles, but not particle mass, was negatively associated with daily PEF deviation. In a recent study, no effects of PM2.5 were found among adult asthmatics [24].

To our knowledge, this is one of the few epidemiological studies to report a significant association between lung function in adult asthmatics and CO. A previous study demonstrated that FEV1 decreased significantly with increasing $\mathrm{CO}$ in the evening of lag 2 among a panel of subjects with advanced COPD in Denver (CO, USA) [36]. PENTTINEN et al. [21] found that $\mathrm{CO}$ was negatively associated with daily morning and evening PEF in adult asthmatics. PARK et al. [23] showed that $\mathrm{CO}$ was significantly associated with $\mathrm{PEF}$ variability and with mean daily PEF in a panel of 64 asthmatic adults. $\mathrm{CO}$ is the product of incomplete combustion, and is mainly produced by motor vehicles in urban areas. A direct association between $\mathrm{CO}$ and asthma lacks biological plausibility. The primary effect of $\mathrm{CO}$ exposure at outdoor concentrations greatly above those observed is indeed hypoxia, which results in confusion, headache and nausea. However, $\mathrm{CO}$ might be a marker for other noxious combustion products. In the present study, air pollutant levels were highly correlated such that it was difficult to separate out the contributions of the individual pollutants. Thus all effects estimates on PEF for CO remained significant, and even increased after controlling for $\mathrm{PM} 10, \mathrm{NO}_{2}$ and $\mathrm{SO}_{2}$ in single and multi-pollutant models.

It is important to note that the adverse effects occurred at levels of $\mathrm{CO}$ and $\mathrm{SO}_{2}$ below current European standards, whereas the daily mean and median concentration of PM10 and $\mathrm{NO}_{2}$ were repeatedly above those standards. This may give rise to some concern that current ambient air quality standards might not be stringent enough to protect human subjects from adverse effects, considering that exposure occurs to a mixture of several pollutants.

The validity of the present findings relies on the long period of the study, the use of repeated measures of lung function in the same individuals, and the method of selecting the study population from the database of drug prescriptions of the Italian National Health Service rather than from clinical series that might be affected by selection bias. Although few studies selected patients randomly from the general population [37], in most studies, patients were selected by general practitioners or chest physicians, and by attendance at chest departments or 
outpatient clinics, and thus were not representative of the average asthmatic population [18, 19, 22, 24, 38]. The selection of patients with the highest rate of bronchodilator prescriptions permitted identification of a cohort of asthmatics enriched in more severe disease. Moreover, the use of an electronic PEF/FEV1 meter avoided inclusion of fabricated measurements and reduced the possibility of data misreporting. Only one other study used the same methodology in adult asthmatics [25].

The study may, however, be affected by some limitations. The size of the study was limited by the small number of subjects, but the number of observations collected was comparable to previous panel studies on adult asthmatics of similar longitudinal design [20, 24, 25]. We chose fewer subjects and a longer period of monitoring in order to maximise the differences in exposure to pollutants known to occur in different seasons. Other panel studies have generally been limited to shorter periods, whereas only few studies in adult asthmatics have covered a period of $>1$ yr $[11,16,37,38]$.

A study design involving five different monitoring sessions over 2 yrs increased the probability of losing participants to follow-up. The number of subjects with less than a third of the measures may appear elevated. Indeed, among these 21 subjects, nine $(43 \%)$ had observations only in the first monitoring section and only one in more than three seasons. Moreover, the total number of observations obtained from these subjects represented a minority of all of the available data (354 out of 1,856 morning measures; 301 out of 1,735 evening measures). For these reasons, the data concerning the 19 subjects who consistently participated in the study were considered more robust. A total of 50 participation days ( $33 \%$ of possible days) was required for inclusion in the main analyses, in agreement with the majority of other similar studies [8, 16, 20, 21, 25, 37].

Since ambient PM2.5 level was not measured at the time of the study, an effect of smaller particles cannot be excluded.

Although the analyses were adjusted for several confounders, i.e. temperature, humidity, pressure, tobacco smoke and corticosteroid use, it was not possible to control for aeroallergens, which were not measured. In order to minimise the influence of grass pollen, the spring season was not included in the study periods. THURSTON et al. [39] considered pollens in their summer study and found no associations between PEF and pollen count. Hence, it is unlikely that pollen would be a significant confounder in the present study since levels are lower in other seasons.

It might be argued that smoking could be a confounder in the present study, although smoking was adjusted for. Asthmatic smokers were deliberately not excluded since the aim was the analysis of a panel representative of the current population of asthmatics, in which a smoking habit is present [40].

In accord with the design of the study, an attempt was made to select asthmatics towards the severe end of the spectrum of the disease. Indeed, only $20 \%$ of the patients had mild asthma. The need for corticosteroids is a component of the severity of the disease, as underlined in the last revision of the GINA guidelines [27]. In addition, there is some evidence that corticosteroid treatment may attenuate air pollutant effects
$[8,11]$, although a consensus on this issue has not been established [19]. For this reason, corticosteroid use was assessed quarterly when the patients were seen, and this information was used as a covariate in the regression model. By design, the present data refer mainly to a moderate-tosevere population, and the imbalance in degree of severity of the sample (together with the small size) prevents meaningful stratified analysis by steroid use.

In conclusion, the present results indicate that lung function, in this panel of adult asthmatics, appears to be affected by exposure to gaseous pollutants, in particular $\mathrm{CO}$, and less so $\mathrm{SO}_{2}$, whereas it does not correlate with exposure to PM. The adverse effects occurred at levels of $\mathrm{CO}$ and $\mathrm{SO}_{2}$ below current European standards.

\section{SUPPORT STATEMENT}

This study was supported by grants from the Regional Agency for Environmental Prevention and Protection in Veneto (Padua, Italy), Ministry of Environment (Rome, Italy) and University of Padua (Padua, Italy).

\section{STATEMENT OF INTEREST}

A statement of interest for this study can be found at www.erj. ersjournals.com $/ \mathrm{misc} /$ statements.dtl

\section{ACKNOWLEDGEMENTS}

The authors would like to thank P. Cadrobbi (Regional Agency for Environmental Prevention and Protection in Veneto (ARPAV), Padua, Italy) for continuous support and helpful discussion, L. Pravato (Data Processing Centre, Local Social Health Centre 16, Padua, Italy) for helping with the extraction of prescription data, A. Benassi (ARPAV) and personnel of the ARPAV for providing data on pollution in Padua, and QUBIsoft (Padua, Italy) for the supply of Piko-1 meters.

\section{REFERENCES}

1 Biggeri A, Bellini P, Terracini B. Meta-analysis of the Italian studies on short-term effects of air pollution - MISA 1996-2002. Epidemiol Prev 2004; 28: Suppl. 4-5, 4-100.

2 Katsouyanni K, Touloumi G, Samoli E, et al. Confounding and effect modification in the short-term effects of ambient particles on total mortality: results from 29 European cities within the APHEA2 project. Epidemiology 2001; 12: 521-531.

3 Atkinson RW, Anderson HR, Sunyer J, et al. Acute effects of particulate air pollution on respiratory admissions. Results from APHEA 2 project. Am J Respir Crit Care Med 2001; 164: 1860-1866.

4 Pope CA 3rd, Dockery DW, Spengler JD, et al. Respiratory health and PM10 pollution. A daily time series analysis. Am Rev Respir Dis 1991; 144: 668-674.

5 Higgins BG, Francis HC, Yates CJ, et al. Effects of air pollution on symptoms and peak expiratory flow measurements in subjects with obstructive airways disease. Thorax 1995; 50: 149-155.

6 Dockery DW, Pope CA 3rd, Acute respiratory effects of particulate air pollution. Annu Rev Public Health 1994; 15: 107-132.

7 Brunekreef B, Dockery DW, Krzyzanowski M. Epidemiologic studies on short-term effects of low levels of major ambient air pollution components. Environ Health Perspect 1995; 103: Suppl. 2, 3-13.

8 Just J, Ségala C, Sahraoui F, et al. Short-term health effects of particulate and photochemical air pollution in asthmatic children. Eur Respir J 2002; 20: 899-906.

9 Delfino RJ, Gong H, Linn WS, et al. Respiratory symptoms and peak expiratory flow in children with asthma in relation to volatile 
organic compounds in exhaled breath and ambient air. J Expo Anal Environ Epidemiol 2003; 13: 348-363.

10 Ranzi A, Gambini M, Spattini A, et al. Air pollution and respiratory status in asthmatic children: hints for a locally based preventive strategy. AIRE study. Eur J Epidemiol 2004; 19: 567-576.

11 Trenga CA, Sullivan JH, Schildcrout JS, et al. Effect of particulate air pollution on lung function in adult and pediatric subjects in a Seattle panel study. Chest 2006; 129: 1614-1622.

12 Holguin F, Flores S, Ross Z, et al. Traffic-related exposures, airway function, inflammation, and respiratory symptoms in children. Am J Respir Crit Care Med 2007; 176: 1236-1242.

13 Tang CS, Chang LT, Lee HC, et al. Effects of personal particulate matter on peak expiratory flow rate of asthmatic children. Sci Total Environ 2007; 382: 43-51.

14 Allen RW, Mar T, Koenig J, et al. Changes in lung function and airway inflammation among asthmatic children residing in a woodsmoke-impacted urban area. Inhal Toxicol 2008; 20: 423-433.

15 Ward DJ, Ayres JG. Particulate air pollution and panel studies in children: a systematic review. Occup Environ Med 2004; 61: e13.

16 Peters A, Goldstein IF, Beyer U, et al. Acute health effects of exposure to high levels of air pollution in Eastern Europe. Am J Epidemiol 1996; 144: 570-581.

17 Peters A, Wichmann HE, Tuch $\mathrm{T}$, et al. Respiratory effects are associated with the number of ultrafine particles. Am J Respir Crit Care Med 1997; 155: 1376-1383.

18 Neukirch F, Ségala C, Le Moullec Y, et al. Short-term effects of lowlevel winter pollution on respiratory health of asthmatic adults. Arch Environ Health 1998; 53: 320-328.

19 Hiltermann TJ, Stolk J, van der Zee SC, et al. Asthma severity and susceptibility to air pollution. Eur Respir J 1998; 11: 686-693.

20 Higgins BG, Francis HC, Yates C, et al. Environmental exposure to air pollution and allergens and peak flow changes. Eur Respir J 2000; 16: 61-66.

21 Penttinen $\mathrm{P}$, Timonen KL, Tiittanen $\mathrm{P}$, et al. Ultrafine particles in urban air and respiratory health among adult asthmatics. Eur Respir J 2001; 17: 428-435.

22 Jansen KL, Larson TV, Koenig JQ, et al. Associations between health effects and particulate matter and black carbon in subjects with respiratory disease. Environ Health Perspect 2005; 113: 1741-1746.

23 Park JW, Lim YH, Kyung SY, et al. Effects of ambient particulate matter on peak expiratory flow rates and respiratory symptoms of asthmatics during Asian dust periods in Korea. Respirology 2005; 10: $470-476$.

24 Lagorio S, Forastiere F, Pistelli R, et al. Air pollution and lung function among susceptible adult subjects: a panel study. Environ Health 2006; 5: 11.

25 Kim DH, Kim YS, Park JS, et al. The effects of on-site measured ozone concentration on pulmonary function and symptoms of asthmatics. J Korean Med Sci 2007; 22: 30-36.
26 Pellegrino R, Viegi G, Brusasco V, et al. Interpretative strategies for lung function tests. Eur Respir J 2005; 26: 948-968.

27 Global Initiative for Asthma. Global Strategy for Asthma Management and Prevention. 2006 Revision. www.ginasthma. com/Guidelineitem.asp? $|1=2 \&| 2=1 \&$ intId $=1388$ Last updated: 2006. Date last accessed: November 15, 2009.

28 Maestrelli P, Zanolla L, Pozzan M, et al. Effect of specific immunotherapy added to pharmacologic treatment and allergen avoidance in allergic asthma. J Allergy Clin Immunol 2004; 113: 643-649.

29 Cazzoletti L, Cerveri I, Corsico A, et al. The current treatment of asthma in Italy. Eur Respir J 2002; 20: Suppl. 38, 427s.

30 Zeger SL, Liang KY. Longitudinal data analysis for discrete and continuous outcomes. Biometrics 1986; 42: 121-130.

31 The European Parliament and the Council of the European Union, Directive 2008/50/EC of the European Parliament and of the Council of 21 May 2008 on ambient air quality and cleaner air for Europe. EUR-Lex 2008; 51: 1-44.

32 Bérubé D, Cartier A, L'Archevêque J, et al. Comparison of peak expiratory flow rate and FEV1 in assessing bronchomotor tone after challenges with occupational sensitizers. Chest 1991; 99: 831-836.

33 Harré ES, Price PD, Ayrey RB, et al. Respiratory effects of air pollution in chronic obstructive pulmonary disease: a three month prospective study. Thorax 1997; 52: 1040-1044.

34 Brauer M, Ebelt ST, Fisher TV, et al. Exposure of chronic obstructive pulmonary disease patients to particles: respiratory and cardiovascular health effects. J Expo Anal Environ Epidemiol 2001; 11: 490-500.

35 Girardot SP, Ryan PB, Smith SM, et al. Ozone and PM2.5 exposure and acute pulmonary health effects: a study of hikers in the Great Smoky Mountains National Park. Environ Health Perspect 2006; 114: 1044-1052.

36 Silkoff PE, Zhang L, Dutton S, et al. Winter air pollution and disease parameters in advanced chronic obstructive pulmonary disease panels residing in Denver, Colorado. J Allergy Clin Immunol 2005; 115: 337-344.

37 Van der Zee SC, Hoek G, Boezen MH, et al. Acute effects of air pollution on respiratory health of 50-70 yr old adults. Eur Respir J 2000; 15: 700-709.

38 Desqueyroux H, Pujet JC, Prosper M, et al. Short-term effects of low-level air pollution on respiratory health of adults suffering from moderate to severe asthma. Environ Res 2002; 89: 29-37.

39 Thurston GD, Lippmann M, Scott MB, et al. Summertime haze air pollution and children with asthma. Am J Respir Crit Care Med 1997; 155: 654-660.

40 Silverman RA, Boudreaux ED, Woodruff PG, et al. Cigarette smoking among asthmatic adults presenting to 64 emergency departments. Chest 2003; 123: 1472-1479. 